\title{
Cuatro historias de migración veracruzana: desertores y retornados en la fragata holandesa Agata Galera [1747]
}

Resumen: Este artículo analiza el fenómeno de la migración transatlántica para lo cual se centra en los pasajeros de un barco, la Agata Galera, una fragata de bandera holandesa y tripulación multinacional que realizaba un viaje de ida y vuelta entre Cádiz y Veracruz. Situamos el barco en su contexto histórico y narramos su último viaje; para luego centrarnos en la tripulación, la cual analizamos como migrantes y al barco como un espacio de socialización intercultural. Finalmente, ofrecemos cuatro historias de migración atípica relativas a pasajeros: un enfermo, dos desertores y un emigrante retornado.

Palabras clave: migración, microhistoria, desertores, marineros.

\section{Four stories of migration in Veracruz: deserters and returnees on the Dutch frigate Agata Galera [1747]}

Abstract: This article analyses the phenomenon of transatlantic migration, focusing on the passengers of a single ship, the Agata Galera, a frigate sailing under Dutch colours with a multinational crew, covering the round trip between Cádiz and Veracruz. The ship's last journey is placed in historical context; then, the article focusses on the crew as migrants and the ship as a site of intercultural socialization. Finally, four atypical personal stories of migration are offered: a sick sailor, two deserters and a returning migrant.

Keywords: migration, microhistory, deserters, sailors.

\section{Quatro histórias da migração em Veracruz: desertores e repatriados na fragata holandesa Agata Galera [1747]}

Resumo: Este artigo analisa o fenômeno da migração transatlântica centrando-se nos passageiros de um navio, a Agata Galera, uma fragata de bandeira holandesa e de tripulação multinacional que fazia uma viagem de ida e volta entre Cádis e Veracruz. Situamos o navio no seu contexto histórico e narramos a sua última viagem; depois, centramonos na tripulação, e analisamo-la em sua condição de migrantes, e o navio como espaço de socialização intercultural. Finalmente, oferecemos quatro histórias de migração atípica em referência aos passageiros do navio: um doente, dois desertores e um emigrante retornado.

Palavras-chave: migração, microhistória, desertores, marinheiros.

Cómo citar este artículo: Alejandro Salamanca Rodríguez, "Cuatro historias de migración veracruzana. Desertores y retornados en la fragata holandesa Agata Galera [1747]”, Trashumante. Revista Americana de Historia Socia/16 [2020]: 58-81. DOI: 10.17533/udea.trahs.n16a04

Fecha de recepción: 26 de junio de 2019

Fecha de aprobación: 18 de diciembre de 2019

Alejandro Salamanca Rodríguez: Máster en Migraciones y Relaciones Interculturales por las universidades Oldenburg [Alemania] y Stavanger [Noruega]. Actualmente es investigador doctoral en Historia por el Instituto Universitario Europeo de Florencia.

Correo electrónico: alejandro.salamanca@revistafua.com 


\section{Cuatro historias de migración veracruzana. Desertores y retornados en la fragata holandesa Agata Galera [1747]}

Alejandro Salamanca Rodríguez

\section{Introducción}

En muchas ocasiones, la migración libre en la Edad Moderna es presentada como Lun fenómeno eminentemente numérico que consiste en grandes números de personas desplazándose de un lugar a otro, casi siempre en los límites que permitieran las leyes y regulaciones. ${ }^{1}$ A pesar de su utilidad para contextualizar los flujos migratorios, los trabajos puramente cuantitativos dejan a veces de lado el elemento humano y simplifican la multiplicidad de variaciones que presentaba la migración, un fenómeno complejo con mucha diversidad. Con el objetivo de mostrar esta complejidad, en este artículo nos vamos a centrar en los migrantes transportados por un único barco.

El 13 de noviembre de 1747, la fragata de bandera holandesa Agata Galera, que encontraba en el tramo final de su viaje de vuelta desde Veracruz a Cádiz, fue capturada por el escuadrón corsario británico The Royal Family cerca del cabo San Vicente. ${ }^{2}$ Gracias a esta captura, una de las tantas que sucedieron en el marco de la

1. Véase Antonio Eiras Roel, "Estructura demográfica, diversidad regional y tendencias migratorias de la población española a finales del Antiguo Régimen", Le migrazioni in Europa, secc. XIII-XVIII, Atti delle "Settimane di Studi" e altri Convegni, ed. Simonetta Cavaciocchi (Firenze: Le Monnier, 1994); Ida Altman, "Emigrants and Society: An Approach to the Background of Colonial Spanish America", Comparative Studies in Society and History 30.1 (1988): 170-190; Ida Altman, "Moving Around and Moving On: Spanish Emigration in the Sixteenth Century", Migration, Migration History, History. Old Paradigms and New Perspectives, eds. Jan Lucassen y Leo Lucassen (Bern / New York: Peter Lang, 1997); Massimo Livi-Bacci, "The Depopulation of Hispanic America after the Conquest", Population and Development Review 32.2 (2006): 199-232. Una excepción interesante es el trabajo de Rosario Márquez Macías, "La emigración española en el siglo XVIII a América”, Rábida 10 (1991): 68-79; Rosario Márquez Macías, "La emigración española a América en la época de las luces”, Españoles de ambas orillas. Emigración y concordia social, coord. Juan Antonio Escudero (Madrid: Sociedad Estatal Lisboa 98, 1998).

2. Captured ship: St Agatha Galley otherwise La Agata Galera (master Don Juan de Rozas, with Arent 
guerra Anglo-hispana de 1739-1748, los historiadores podemos acceder a la gran mayoría de los documentos que se encontraban a bordo del navío. ${ }^{3}$

Los documentos de la Agata se encuentran en la colección Prize Papers del archivo de la Corte Británica del Almirantazgo, actualmente ubicados en los Archivos Nacionales británicos en Kew. Este fondo documental, no lo suficientemente explotado por los historiadores, ${ }^{4}$ nos permite acceder a algunos documentos que no se encuentran en los archivos habituales. Los británicos confiscaban la totalidad de los papeles que encontraban a bordo, lo que incluía dibujos, naipes o cartas personales que eran archivados bajo el genérico nombre de ship's papers. Aunque en la mayoría de las cajas de la colección (que está organizada alfabéticamente por nombre de barco) los ship's papers son documentos comerciales y legales de poco interés para el historiador de las migraciones (utilísimas, eso sí, para historiadores de otros campos), en algunos casos, como en el de la Agata, encontramos fuentes primarias interesantísimas: correspondencia familiar, el registro de tripulación y el libro de a bordo (que refleja las deserciones), documentos médicos, entre otros.

Este artículo se centra en el barco como espacio de trabajo de migrantes de toda Europa y medio de transporte para personas que emigraron a Veracruz fuera de los canales habituales, o que volvían de Nueva España tras una experiencia migratoria fallida. En primer lugar, ofreceremos información sobre el último viaje de la Agata. En segundo lugar, nos centraremos en la tripulación del barco, compuesta por migrantes de toda Europa.Y, luego, el artículo desarrollará las cuatro historias de migración que encontramos a bordo del buque: la de un español que consiguió permanecer en México sin que las autoridades lo buscasen; la de un marinero holandés que desertó en Veracruz; la de un negro libre que abandonó el barco en el mismo puerto, y la de un adolescente que regresaba a España con cartas de recomendación.

\section{El último viaje de la Agata}

En 1747, Cádiz era una ciudad global repleta de personas, mercancías y barcos que disfrutaba del monopolio del comercio con la América española. Las dos instituciones más importantes que regulaban los movimientos de bienes y personas

Tuyn the Dutch captain and pilot), 1747.TNA, Londres, High Court of Admiralty 32/94/17. El episodio aparece reflejado en la biografia coetánea del comandante corsario: George Walker, The Voyages and Cruises of Commodore Walker, During the Late Spanish and French Wars, vol. 2 (London: A. Miller, 1760) 256.

3. Véase Alejandro Salamanca Rodríguez, "A Floating Microcosm: Histories of Transatlantic Migration in 1747" (Tesina de máster en Migraciones y Relaciones Interculturales, Universidad de Oldenburgo, 2019).

4. Por fortuna, eso va a cambiar dentro de relativamente poco. El Prize Papers Project, liderado por la Universidad de Oldenburgo en Alemania, está llevando a cabo un proceso de digitalización e indexación de la colección. Si bien la tarea es ingente, se espera que algunos de los documentos salgan a la web en los dos próximos años. Véase Prize Papers Project, The Prize Papers Project: Archiving an Early Modern Unarchived Archive. https://www.prizepapers.de/ (10/12/2019). 
entre Europa y América: la Casa de Contratación y el Consulado, se trasladaron de Sevilla a Cádiz en décadas anteriores. Cada barco que zarpaba o regresaba de América debía hacer una parada en la ciudad, lo que la convirtió en un imán para los migrantes de todos los lugares y orígenes sociales, desde comerciantes extranjeros ricos que buscaban buenos negocios hasta pobres en buscaban de empleo o un viaje a las Indias. ${ }^{5}$ La ciudad, no obstante, estaba afectada por la guerra que desde 1739 enfrentaba a españoles y británicos. No hubo ataques significativos a las ciudades ni escasez de suministros, pero los corsarios británicos de vez en cuando interceptaban uno de los navíos que salían o viajaban al puerto, con lo que conseguían apresar a los marineros, causar pérdidas a los mercaderes e impedir a los migrantes y pasajeros llegar a sus destinos. El conflicto también causó escasez de marineros en la mayoría de los puertos de la España peninsular, ya sea porque habían sido reclutados por la armada o capturados por el enemigo, o porque se habían unido a un barco extranjero para evitar servir en las embarcaciones militares. ${ }^{6}$

Conscientes de su inferioridad naval y con el objetivo de evitar pérdidas y garantizar la continuidad del comercio y las comunicaciones entre ambas costas del Atlántico, los españoles decidieron suspender temporalmente el tradicional sistema de flotas y galeones y permitir que barcos individuales, llamados "navíos de registro" o "navíos sueltos", surcaran las rutas entre la España peninsular, América y Filipinas. ${ }^{7}$ Durante los nueve años de guerra, 120 barcos de registro navegaron a Nueva España y al resto de América, aunque más de la mitad se perdieron en sus viajes de regreso. Estos buques, muchos de bandera neutral como la Agata, lograron mantener los mercados abiertos y aseguraron el flujo de mercancías y personas entre ambas orillas del Atlántico a pesar de la amenaza que representaban los británicos. En términos cuantitativos, la política fue un éxito. La cantidad de bienes y divisas que fluían desde los principales puertos de América del Sur y Central a España aumentó constantemente durante y después de la guerra, como muestra Allan Kuethe. ${ }^{8}$ Algunas de las características que muestra la Agata, entre ellas navegar con bandera holandesa y sin protección, fueron una consecuencia directa de las reformas en la política comercial que el Imperio español había implementado después de la guerra con los británicos.

5. Manuel Bustos Rodríguez, Cádiz en el sistema atlántico. La ciudad, sus comerciantes y la actividad mercantil (1650-1830) (Madrid: Sílex Ediciones / Universidad de Cádiz, 2005).

6. Antonio Laborda y Santiago Rodríguez Aedo, Historias de la Real Armada y asociados. Prensa y corsarios españoles en la Guerra del Asiento, 1739-1748 (Madrid: La Hoja del Monte, 2018) 111.

7. Para el efecto de las guerras en el comercio español, véase Geoffrey J. Walker, Spanish Politics and Imperial Trade, 1700-1789 (London: Palgrave Macmillan Limited, 2016) 67-71. Información variada sobre los cambios en las rutas comerciales durante el siglo XVIII se puede encontrar en Demetrio Ramos, "Las rutas comerciales de Indias y de América del Norte", España y el mar en el siglo de Carlos III,Vicente Palacio Atard y otros (Madrid: Marinvest, 1989) 202-205.

8. Allan J. Kuethe y Kenneth J. Andrien, El mundo atlántico español durante el siglo XVIII. Guerra y reformas borbónicas, 1713-1796 (Bogotá: Editorial Universidad del Rosario / Banco de la República, 2018) 157-158. 
La Agata partió de Cádiz por última vez el 24 de marzo de 1747. Los preparativos para el viaje habían comenzado en octubre del año anterior cuando el armador del barco, Francisco de Lucas y Ledesma, vecino de Sanlúcar de Barrameda, ${ }^{9}$ caballero de la Orden de Calatrava, ${ }^{10}$ y propietario de al menos otro barco que comerciaba con Veracruz, el San Francisco, ${ }^{11}$ solicitó permiso a las autoridades para fletar un barco a Nueva España. ${ }^{12}$ El capitán de la Agata sería un holandés residente en Cádiz llamado Aren Tuyn, quien no hablaba español con fluidez. En su presentación formal para ser registrado como capitán que iba a América, Tuyn recibió la asistencia de Theodoro del Rey, un vecino de Cádiz que hablaba holandés y español y que declaró que Tuyn era una persona de confianza. Juan de Rosas, alguacil mayor de la ciudad de Sanlúcar de Barrameda, fue nombrado maestre de la fragata por Ledesma unos dos meses antes del viaje.

Una vez cumplidas las formalidades y eliminados algunos obstáculos burocráticos, de Rosas y Tuyn comenzaron su trabajo. El 27 de febrero, capitán y maestre contrataron formalmente a la tripulación de la Agata y registraron a 51 hombres en la lista de enrolados de la nave: 11 oficiales, 36 marineros, 2 pajes y 2 sirvientes. Siguiendo la práctica habitual, de Rosas anotó el nombre y apellido, nombre del padre, edad, lugar de origen y descripción física de los miembros de la tripulación, de quienes hablaremos más adelante. ${ }^{13}$ Una vez contratada la tripulación, Tuyn y de Rosas comenzaron a cargar mercancías de diferentes comerciantes del área de la bahía de Cádiz.

La Agata, finalmente, partió de Cádiz el 24 de marzo y llegó a Veracruz el 26 de mayo. Tras descargar el barco, los marineros y los oficiales pudieron disfrutar varios días libres; algunos de ellos lograron desertar y entrar ilegalmente a las Indias. En Veracruz, el maestre Juan de Rosas envió noticias a sus familiares en la Ciudad de México, se encontró con dos parientes a los que llevaba años $\sin$ ver, ${ }^{14}$ asistió a

9. Sobre el término vecino y sus implicaciones en la monarquía hispánica, véase Tamar Herzog, Defining Nations. Immigrants and Citizens in Early Modern Spain and Spanish America (New Haven / London:Yale University Press, 2003). Por otra parte, una interesante obra sobre el municipio durante el periodo es Narciso Climent Buzón, Historia social de Sanlúcar de Barrameda. En busca de nuestro pasado, vol. 3 (Sanlúcar de Barrameda:Asociación Sanluqueña de Encuentros con la Historia y el Arte, 2008).

10. "Ledesma, Francisco Lucas de", 1744. AHN, Madrid, signatura OM-Caballeros_Calatrava, exp.1372 bis.

11. "Registros de ida de las naos sueltas que fueron a Veracruz", 1747. AGI, Sevilla, Contratación 1513, n. 1, ramo 1.

12. "Registros de ida de las naos sueltas que fueron a Veracruz", 1747. AGI, Sevilla, Contratación 1513, n. 1 , ramo 1.

13. "Muster roll of the ship Agata Galera", 1747.TNA, Londres, High Court of Admiralty 32/94/17/ SP165. Refleja la práctica estándar. Otros documentos análogos siguen fórmulas parecidas: "Muster roll for the ship San Cayetano", 6 de marzo de 1745.TNA, Londres, High Court of Admiralty 32/100/3/SP12.

14. Se trataba de su hermano Fernando de Rosas y su tío Miguel Pavón. Letter from Fernando de Rosas in Mexico City to Juan de Rosas, 6 de julio de 1747.TNA, Londres, High Court of Admiralty 32/94/117/SP118. 
algunas reuniones con las autoridades del virreinato y recogió algunas cartas para Sanlúcar de Barrameda. También se reunió con el factor Juan Ruiz de España, quien pagó los salarios y gastos del viaje de regreso y dio a de Rosas un paquete de cartas para su familia, amigos y socios comerciales. A finales de agosto la Agata cargó mercancías y zarpó de nuevo, se detuvo en Cuba para realizar algunas compraventas antes de reanudar su vuelta a España, lo que hubiera tomado unas seis semanas, si los corsarios británicos no les hubieran apresado.

\section{Los migrantes de la Agata}

La Agata era un barco lleno de migrantes de toda Europa. Los marineros en la Edad Moderna, al igual que sus homólogos actuales, eran una fuerza de trabajo móvil que pasaba largos periodos de tiempo lejos de sus países de origen, muchos de ellos sin regresar jamás. Aunque la mayoría de los tripulantes de la Agata no se asentara en un nuevo país, tenemos que pensar en ellos como migrantes laborales que se desplazaban junto a su lugar de trabajo. Los marineros a menudo habían emigrado a puertos comerciales antes de enrolarse en una nave, ${ }^{15}$ y entre distintos empleos muchos de ellos permanecían en puertos extranjeros, lejos de sus hogares.

En la visita oficial antes de la salida de la Agata, Juan de Rosas había declarado que el barco contaba con un capitán, un maestre (él mismo), un cirujano, un notario, dos pilotos, dos contramaestres, un guardián, dos condestables, un cocinero, 37 marineros y dos pajes; 51 hombres en total. Sin embargo, la lista de tripulación de la Agata era distinta: teóricamente, el número de personas en el barco era también de 51, pero había un oficial y un marinero menos y a cambio dos criados fueron añadidos en su lugar. Como la Agata era un barco holandés, Juan de Rosas no especificó en la lista de enrolados las diferentes categorías salariales de los marineros, sin embargo, encontramos información sobre su edad y lugar de origen. La mayoría de los miembros de la tripulación de la Agata estaban en la mitad de la veintena: la edad media de los marineros era de 27 años, mientras que la de los oficiales era 29 (Figura 1). El miembro más viejo de la tripulación era el marinero Juan Westalen, procedente de Hamburgo y con 43 años de edad. El más joven era Bernardo de Bur, un paje de Ámsterdam "muy rubio" de 16 años.

Todos los oficiales procedían de Ámsterdam excepto de Rosas, Francisco López y Vicente Antonio Villa. Francisco López tenía 25 años y decía venir de Cádiz. Su responsabilidad en el barco no está clara; en algunos documentos se le menciona como notario y en otros como asistente. En cualquier caso, fue enviado por Ledesma para supervisar a la tripulación holandesa y ayudar al maestre firmando

15. Para un análisis del mercado laboral marítimo en los Países Bajos durante el periodo, véase Alexander Klein y Jelle van Lottum, "The Determinants of International Migration in Early Modern Europe: Evidence from the Maritime Sector, c. 1700-1800”, School of Economics Discussion Papers 1710 (2017): 1-47. 
Figura 1. Miembros de la tripulación por grupo de edad, como se indica en el registro de tripulación de la Agata, 27 de febrero de 1747

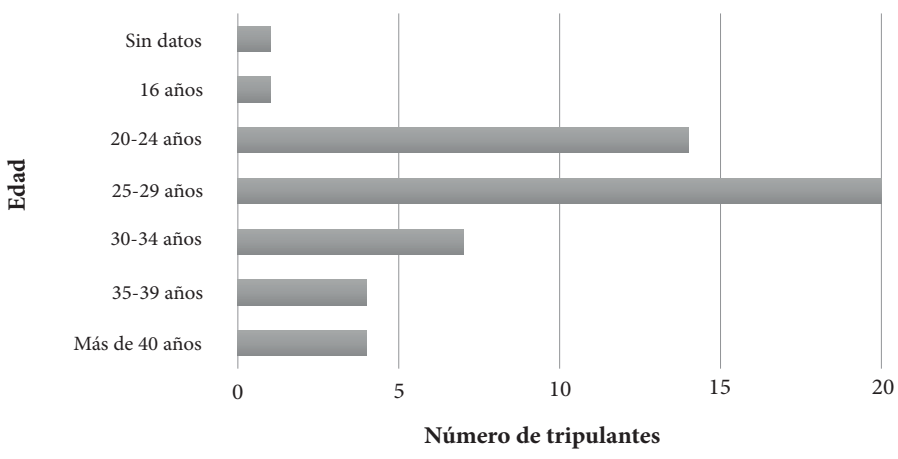

Fuente: "Muster roll of the ship Agata Galera", 1747. TNA, Londres, High Court of Admiralty 32/94/17/SP165.

certificados, cartas y todos los documentos oficiales que el barco pudiera necesitar. ${ }^{16}$ Vicente Antonio Villa, viudo de 31 años, era de Tenerife. Aparece como el "piloto por parte del fletador”. TantoVilla como López pudieron llevar un cofre o frasquera con su ropa y espacio para algunos licores, una práctica común que permitía a los oficiales ganar un dinero adicional vendiendo las bebidas en México. ${ }^{17}$

Tan solo doce de los marineros de la Agata eran españoles. Once de ellos procedían de Andalucía, una región con un desempleo estacional secular. ${ }^{18}$ El resto de los marineros de la Agata provenían de diferentes lugares de Europa, la mayoría de ellos de países considerados neutrales en la guerra de 1739-1748 (Figura 2). En caso de captura por parte de corsarios británicos tener una tripulación neutral podría impedir que el barco fuera confiscado, aunque este no fue el caso de la Agata. A partir de los documentos del barco es imposible saber si los marineros estaban ya embarcados al llegar a Cádiz o si fueron contratados allí. Dada la prosperidad de la ciudad y los salarios relativamente altos que ofrecía a los marineros, es posible que muchos de los miembros de la tripulación hubieran emigrado previamente a Cádiz. Por otra parte, también es posible que algunos de los marineros fueran contratados en los Países Bajos. El mercado de trabajo marítimo holandés contaba con

16. "Como especificado en las órdenes de Ledesma para el amo de la nave. Francisco d. Ledesma, Horden que le dan a don Juan de Rozas y Sespedes para que las observe durante la navegación del navío Olandés nombrado la Agata Galera que está a su cargo", 1747. TNA, Londres, High Court of Admiralty 32/94/117/SP107.

17. Aingeru Zabala, "La vida cotidiana en los navíos de comercio", España y el mar en el siglo de Carlos III,Vicente Palacio Atard y otros (Madrid: Marinvest, 1989) 185.

18. Véase Jesús Manuel González Beltrán, "Desempleo y pobreza en la agricultura de la Baja Andalucía en el siglo XVIII”, Chronica Nova 37 (2011): 237-270; Jesús Manuel González Beltrán, “Trabajadores agrícolas y conflictividad laboral en la Andalucía del siglo XVIII”, Trocadero 17 (2005): 9-35. 
Figura 2. Lugar de origen de los tripulantes de la Agata como aparece en el rollo de mostaza, 27 de febrero de 1747

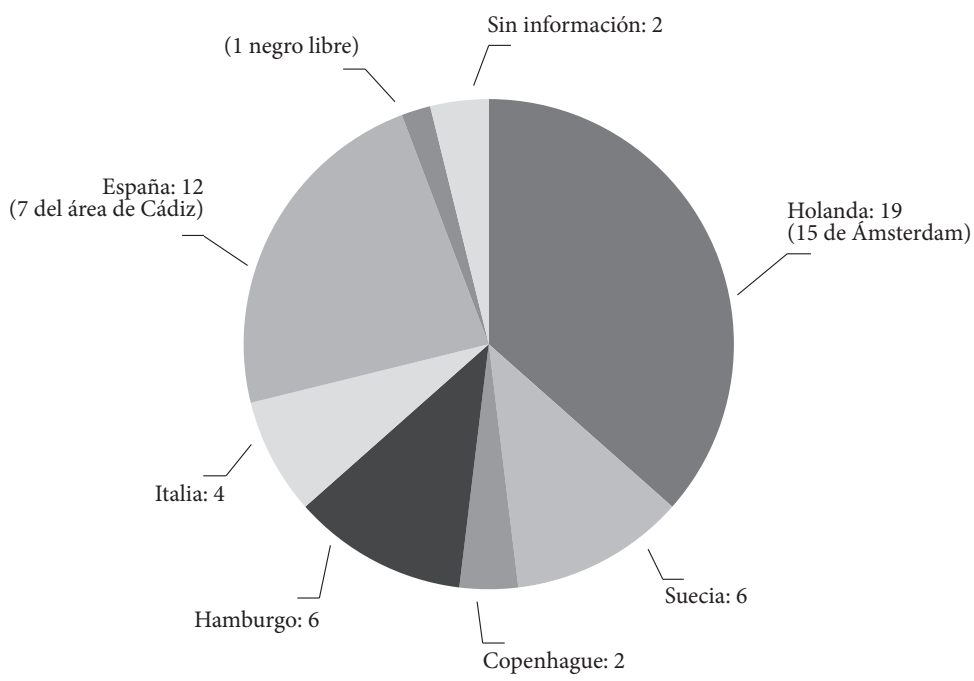

Fuente: "Muster roll of the ship Agata Galera", 1747. TNA, Londres, High Court of Admiralty 32/94/17/SP165.

marineros de todo el norte de Europa debido al considerable tamaño de la flota holandesa y la relativa escasez de marineros nativos. Durante el siglo XVIII más de la mitad de los tripulantes de los buques mercantes holandeses eran extranjeros, la mayoría de ellos procedentes del norte de Alemania, Dinamarca y Suecia como era el caso de la tripulación de la Agata. ${ }^{19}$ Estos marineros no tenían por qué haber sido contratados en Ámsterdam, ya que los barcos holandeses solían buscar mano de obra en los puertos alemanes o escandinavos. Ambas hipótesis son plausibles y no mutuamente excluyentes, pues los Países Bajos y España tuvieron una estrecha conexión durante el periodo.

La comunidad holandesa en Cádiz era especialmente importante, y en 1740 era una de las colonias extranjeras más prósperas de la ciudad. Desde el último cuarto del siglo XVII se había producido una constante afluencia de mercaderes y marineros holandeses a Cádiz: el comercio español en Europa dependía en gran medida de las empresas holandesas, que a su vez dependían de la ciudad, puerta de entrada a las Américas en un momento en que el comercio mediterráneo estaba

19. Jelle van Lottum y otros, "Sailors, National and International Labour Markets and National Identity,1600-1850", Shipping and Economic Growth, 1350-1850, ed. Richard W. Unger (Leiden / Boston: Brill, 2011) 322-326. Los lugares de origen de los miembros de la tripulación de la Agata también coinciden con los más comunes en La Compañía Holandesa de las Indias Orientales. Véase Jelle van Lottum, "Origins of individuals in VOC Careers Dataset". Huygens INGKNAW, https://twitter.com/jellevanlottum/status/1118872252509040641 (03/04/2020). 
en crisis. Las casas comerciales holandesas y flamencas tenían una presencia importante en Cádiz, donde cooperaron con las familias mercantes españolas. ${ }^{20}$ Ana Crespo sostiene que los holandeses estaban plenamente integrados en la ciudad y caracteriza la relación entre españoles y extranjeros en Cádiz como "alianza, interdependencia y convivencia”. ${ }^{21}$ Algunas familias holandesas se asentaron en la ciudad durante generaciones y establecieron fuertes vínculos con los clanes patricios locales a la vez que se desarrollaba un ciclo permanente de migración circular de hombres holandeses jóvenes y solteros que trabajaban como marineros o agentes comerciales en España. Crespo afirma que "la afluencia migratoria a Cádiz fue mucho más importante que la migración holandesa a sus propios enclaves americanos". ${ }^{22}$ Aren Tuyn, el capitán de la Agata, era uno de estos migrantes. Como hemos visto, el capitán no hablaba español con fluidez, pero estaba registrado como residente de la ciudad, lo que demuestra que había una comunidad holandesa activa en la que podía confiar. No es difícil imaginar que la mayoría de los oficiales ya formaban parte de la red del capitán, ya que el puesto requería trabajadores experimentados y de confianza. Con las excepciones nombradas anteriormente, todos los oficiales provenían de Ámsterdam, la ciudad natal del capitán.

Una de las prácticas migratorias de las que tenemos evidencia en la Agata es la deserción, aunque esta no siempre implicaba una migración efectiva. Siguiendo la costumbre, los marineros enrolados en la Agata recibieron en Cádiz un adelanto de sus salarios tras ser formalmente contratados y que sus nombres fueran anotados en la lista de tripulantes. Seis marineros (dos venecianos, dos holandeses y dos sanluqueños) no regresaron a la Agata antes de su partida. Este tipo de deserción era relativamente común, y por esa razón las listas de tripulantes contaban normalmente con la descripción física de los marineros contratados, ya que podía servir para identificar a los desertores. Cuatro días después de la partida el capitán se percató de que faltaban algunos marineros y pidió al piloto español y al escribano que actuasen como testigos y redactasen una nota formal en la que notificaran las deserciones al maestre. ${ }^{23}$ Los marineros que desertaron en Cádiz tuvieron suerte. Debido a que la Agata fue capturada, el maestre nunca pudo informar de su ausencia a las autoridades en España. Los venecianos y los holandeses que se quedaron en Cádiz probablemente no tuvieron problemas para encontrar nuevas oportunidades de empleo en una ciudad donde había una gran demanda de marineros y existían importantes comunidades extranjeras.

20. Ana Crespo Solana,"Legal Strategies and Smuggling Mechanisms in the Trade with the Hispanic Caribbean by Foreign Merchants in Cadiz: The Dutch and Flemish Case, 1680-1750", Jahrbuch für Geschichte Lateinamerikas 47.1 (2010): 181-212.

21. Crespo Solana 183.

22. Crespo Solana 188.

23. Diego Carrillo, "Notification of desertions", 28 de marzo de 1747.TNA, Londres, High Court of Admiralty 32/94/17/SP105. 
En Veracruz otros siete tripulantes de la Agata no volvieron al barco para el viaje de vuelta. Uno de ellos, Antonio Cordero, dejó el barco con el permiso del capitán y logró migrar a México sin ser perseguido por las autoridades como veremos en la siguiente sección. Los otros seis se convirtieron en desertores y migrantes irregulares. El maestre Juan de Rosas solicitó a las autoridades veracruzanas su arresto y devolución a la Agata. Cuatro de los desertores parecían ser españoles; también había un "negro libre" y un marinero holandés. ${ }^{24}$ Si los cuatro desertores lograron salir de Veracruz y establecerse en otra localidad, es posible que no encontraran muchos problemas con las autoridades. Además, eran marineros o criados y no disfrutaban de una posición acomodada, por lo que es poco probable que en el caso de ser capturados hubieran sido enviados de vuelta a España. Si los desertores capturados no tenían dinero, las autoridades tendrían que pagar su viaje a España, por lo que lo más probable es que en caso de ser apresados se hubieran limitado a permanecer en prisión durante algún tiempo. Como veremos a continuación, el "negro libre" Thomas Villanueva y el desertor holandés Juan Ricce pueden haber encontrado más dificultades para adaptarse a la vida en la Nueva España.

\section{Cuatro historias de migración atípica}

Si excluimos fenómenos como la migración circular y casos especiales como los marineros, la migración puede ser definida como un proceso que normalmente consta de dos partes: el desplazamiento de un lugar a otro y la adaptación e integración en una nueva sociedad. Las personas que quieren migrar necesitan encontrar una manera de trasladarse a su país de destino, ya sea legalmente o por canales irregulares. Una vez llegan, deben establecerse y encontrar su lugar en un orden social desconocido. Las fuentes archivísticas relacionadas con la Agata ofrecen información sobre cómo viajaban los migrantes, pero no tanto sobre lo que sucedió después de que se establecieran. La mayoría de los migrantes de la Agata eran marineros que no dejaron la nave tras su estancia en Veracruz, de modo que no se asentaron en México. No obstante, algunos miembros de la tripulación desertaron, convirtiéndose así en inmigrantes irregulares.

Formalmente, la migración y el comercio entre Europa e Hispanoamérica estaban estrictamente regulados. Los extranjeros y las personas sin "limpieza de sangre" quedaron teóricamente excluidos del comercio y la migración al Nuevo Mundo. ${ }^{25}$ Las Leyes de Indias dictaban que solamente los nativos de los

24. Juan de Rosas y Céspedes, "Lista de la gente que ha desertado de la fragata Olandesa nombrada la Agata Galera”, 17 de agosto de 1747.TNA, Londres, High Court of Admiralty 32/94/17/SP133.

25. "Un extranjero era cualquier persona (excluyendo esclavos) nacido fuera de España o de las Indias". Charles F. Nunn, Foreign Immigrants in Early Bourbon Mexico, 1700-1760 (Cambridge: Cambridge University Press, 1979) 15. Para obtener una colección detallada de ensayos sobre el tema de la "limpieza de sangre", véase Nikolaus Böttcher y otros, coords., El peso de la sangre. 
reinos de España podían inmigrar y establecerse en las posesiones españolas. ${ }^{26}$ Para viajar a América desde España era necesario solicitar una licencia en la Casa de Contratación. Solo aquellos que cumplían con los criterios establecidos (nacionalidad española, religión católica, ausencia de antepasados judíos o musulmanes, ausencia de antecedentes judiciales negativos, color de piel adecuado) recibirían permiso para navegar a América. ${ }^{27}$ Aquellos que no podían obtener una licencia o pagar los costes del viaje encontraban formas alternativas tales como viajar como sirvientes o empleados de otra persona, ${ }^{28}$ desertar de un barco una vez en el Nuevo Mundo, o tratar de escabullirse a bordo como polizones. ${ }^{29}$

Las leyes castigaban severamente no solo a los migrantes y polizones ilegales, sino también a todo aquel que los ayudara u ocultase, especialmente los capitanes de barco. ${ }^{30}$ Este hecho revela algunas prácticas generalizadas como la venta de licencias de sirvientes a personas que deseaban migrar por parte de los pasajeros ricos, o el transporte de pasajeros no autorizados por algunos capitanes. En el siglo XVIII las autoridades españolas estaban preocupadas por el declive demográfico en la península, y activamente trataron de limitar la migración a las Américas. Solo funcionarios públicos, clérigos, encomenderos con sus sirvientes y parientes cercanos de migrantes ya asentados en las Américas recibían permiso para cruzar el Atlántico. Como consecuencia, el número de migrantes no autorizados o irregulares aumentó. ${ }^{31}$

En la Agata tenemos constancia de varios intentos de migración irregular de España a México, un caso de legalidad dudosa y un migrante retornado, además de numerosas cartas de o para emigrantes peninsulares en México. Los cuatro ejemplos que presentamos a continuación muestran la multiplicidad de posibilidades de

Limpios, mestizos y nobles en el mundo hispánico (México: El Colegio de México, 2011).

26. Las coronas españolas de Castilla y Aragón se unificaron jurídicamente al final de la Guerra de Sucesión (1713). Las leyes y costumbres de Castilla luego se extendieron a los otros reinos. Originalmente, solo a los nativos de Castilla se les permitió migrar y comerciar con las Américas.

27. Las Leyes de Indias dan indicaciones específicas sobre el migrante ideal para la Corona. Se daba prioridad a los hombres sobre las mujeres, quienes por lo general necesitaban estar casadas si querían migrar. Los negros, mulatos, gitanos, protestantes y otros "indeseables" quedaban estrictamente prohibidos. Véase "De los passageros, y licencias para ir a las Indias, y bolver á estos Reynos", Recopilación de las Leyes de los reynos de las Indias, t. 4, libro IX, título XXVI (Madrid: Julián de Paredes, 1681) ff. 1r-11v.

28. William O'Reilly, "Movements of People in the Atlantic World, 1450-1850", The Oxford Handbook of the Atlantic World, 1450-1850, eds. Nicholas Canny y Philip Morgan (Oxford: Oxford University Press, 2011) 313.

29. Sobre el fenómeno de los polizones véase Bibiano Torres Ramírez y José J. Hernández Palomo, eds., Andalucía y América en el siglo XVIII. Actas de las IV Jornadas de Andalucía y América Universidad de Santa María de la Rábida, marzo-1984 (Sevilla: Escuela de Estudios Hispano-Americanos de Sevilla, 1985) 252-269.

30. "De los passageros, y licencias para ir a las Indias" $f .1 \mathrm{v}$.

31. Márquez Macías, "La emigración española en el siglo XVIII” 68-73. 
la migración a mediados del siglo XVIII, un fenómeno que no siempre pudo ser controlado por las autoridades.

\subsection{Un marinero atrapado en la zona gris}

Antonio Cordero, un marinero de veinticinco años nacido en Jerez de la Frontera, partió a Puebla con el permiso del maestre de la Agata. Su estatus legal no está claro, pero Juan de Rosas no incluyó el nombre de Cordero en la lista de desertores que envió a las autoridades de Veracruz en la que solicitaba su búsqueda, captura y retorno a la nave. ${ }^{32}$ A Cordero se le permitió salir de la nave porque se encontraba enfermo. ${ }^{33}$ No hay detalles sobre su enfermedad, solo consta que partió a la ciudad de Puebla con el permiso del maestre y capitán para su "curación" en julio de $1747 .{ }^{34} \mathrm{Su}$ caso debe haber sido especial, ya que otros dos miembros de la tripulación que estaban enfermos (un marinero con sífilis y un criado o escribano con una hernia inguinal) permanecieron en el barco. ${ }^{35}$ Puebla, el destino de Cordero, era una ciudad más grande que Veracruz y tenía mejores instalaciones médicas. Había al menos siete hospitales en la ciudad; uno de ellos había sido construido específicamente para los inmigrantes españoles, ${ }^{36}$ y otro para los enfermos de sífilis. ${ }^{37}$ Solo podemos especular. Puede que Cordero contrajera una enfermedad venérea que le impidió continuar embarcado, o tal vez el maestre y el capitán decidieron enviarlo a Puebla porque no podían pagar un médico o un hospital para él en Veracruz y prefirieron que fuera atendido por los Hermanos de la Caridad, una orden religiosa que se ocupaba de los enfermos y gestionaba una red de hospitales a lo largo de la ruta desde Veracruz hasta Ciudad de México. ${ }^{38}$

Si Cordero sobrevivió (las tasas de mortalidad en los hospitales mencionados anteriormente eran de alrededor del 15\%), es posible que permaneciese en México o regresara a España en algún momento. Dado que no había ningún procedimiento legal pendiente en su contra, muy fácilmente podría haberse establecido en la Nueva España e incluso alcanzar el estatus de "vecino" en alguna ciudad. Cordero, un marinero enfermo, no debe haber tenido mucho dinero, y como su aspecto parece haber sido poco notable (su descripción física en la lista de tripulantes solo dice que tenía "buen cuerpo"), existe la posibilidad de que se integrara

32. Juan de Rosas y Céspedes, "Lista de la gente que ha desertado de la fragata Olandesa nombrada la Agata Galera", 17 de agosto de 1747.TNA, Londres, High Court of Admiralty 32/94/17/SP133.

33. "List of sick and deserted sailors", 1747.TNA, Londres, High Court of Admiralty 32/94/17/SP85.

34. "Muster roll of the ship Agata Galera", 1747.TNA, Londres, High Court of Admiralty 32/94/17/ SP165.

35. Alfonso García, "Certificate of medical visitation”, 18 de julio de 1747. TNA, Londres, High Court of Admiralty 32/94/17/SP134.

36. Veáse Josefina Muriel, Hospitales de la Nueva España. Fundaciones del siglo XVI, t. 1 (México: Universidad Nacional Autónoma de México, 1990) 149-152.

37. Muriel 177-190.

38. Muriel 201-347. 
sin problemas en la sociedad urbana de la Nueva España. Según Tamar Herzog, los migrantes humildes con los marcadores de identidad adecuados solo necesitaban vivir y participar en una comunidad el tiempo suficiente para ganarse la confianza de los lugareños y pasar a ser considerados vecinos, sin necesidad de cartas oficiales de naturalización. ${ }^{39}$ No obstante, no sabemos si Cordero llegó a recuperarse de su enfermedad o a salir siquiera del hospital. Otra posibilidad es que regresara a España, para lo cual habría sido preciso pagar por su viaje o trabajar de nuevo como marinero.

\subsection{Un holandés en Nueva España}

Juan Ricce (o Rize) era un marinero de 36 años originario de Rotterdam. Tenía ojos azules y, según decía, su padre también se llamaba Juan. Los escribanos españoles solían hispanizar los nombres extranjeros, por lo que no podemos estar seguros si este era su verdadero apellido. De hecho, la única información de la que podemos estar seguros es el color de sus ojos, ya que Ricce podría haber mentido sobre su nombre, edad y lugar de origen, una práctica común entre los marineros que pretendían desertar. El holandés no regresó para la revisión de la tripulación el 12 de agosto, ni fue encontrado por las autoridades cuando Juan de Rosas exigió su detención en Veracruz. ${ }^{40}$ Solo podemos especular sobre el destino de Ricce. Si tuvo una intención genuina de establecerse en el Nuevo Mundo y logró sobrevivir al nuevo clima y enfermedades, es probable que dejara Veracruz y evitara las zonas costeras, donde las autoridades estarían buscando extranjeros y desertores. Puede que el marinero supiera español o hubiera aprendido algo a bordo de la Agata u otros barcos, aunque debemos recordar que el propio capitán no hablaba español con fluidez y, probablemente, se utilizó algún idioma criollo a bordo.

Aun así, Ricce podría haber despertado algunas sospechas entre la población local, aunque afortunadamente los habitantes de México no parecían interesados en denunciar a los extranjeros ante las autoridades, si estos respetaban las costumbres y normas sociales. Según Charles Nunn, los extranjeros que se encontraban irregularmente en México durante el siglo XVIII podían pasar desapercibidos sin dificultad. Mientras Ricce fingiera ser católico (si es que no lo era ya) y se abstuviera de expresar ideas heréticas, no tendría problemas con las autoridades religiosas. Si no se dedicaba al comercio o amasaba una fortuna significativa, el virreinato no se interesaría en confiscar sus bienes o deportarlo, especialmente si no tenía los medios para pagar un pasaje de vuelta a España.Y si lograba casarse y producir descendencia, su deportación sería aún más improbable, aunque casarse implicaba tratar con la burocracia virreinal. Como explica Nunn, cuando los extranjeros se casaban, sus nacionalidades eran normalmente reveladas a toda

39. Normalmente solo las personas adineradas que podían ser percibidas como una amenaza por la comunidad local tenían problemas para ser reconocidos como vecinos. Véase Herzog 117.

40. Juan de Rosas y Céspedes, "Lista de la gente que ha desertado de la fragata Olandesa nombrada la Agata Galera”, 17 de agosto de 1747.TNA, Londres, High Court of Admiralty 32/94/17/SP133 
la comunidad, aunque en la mayoría de las ocasiones eso no conducía a su detención por las autoridades. Esto "indica una tolerancia no oficial e informal pero generalizada hacia los extranjeros que estaban tratando de convertirse en buenos ciudadanos y miembros dignos de la comunidad". ${ }^{41}$

Sin embargo, es casi imposible saber si Ricce se casó alguna vez o cómo y dónde vivió en México. Es factible que para huir de las autoridades de Veracruz cambiase su identidad, tal vez eligiendo un nombre diferente o afirmando proceder de un país católico. En Nueva España había una mayor concentración de extranjeros europeos en las ciudades en las cuales era más fácil mezclarse con el resto de la población. Ricce no era joven, por lo que tal vez contase con algunos ahorros para pagar su viaje desde Veracruz. Si por ejemplo hubiese sido un trabajador especializado en carpintería (algo bastante probable dada su experiencia como marinero), el holandés podría haber entrado al servicio de un artesano en un taller e incluso haber abierto uno propio. Siempre y cuando no muriera de ninguna enfermedad poco después de su deserción, el hecho de que en los registros de archivo no aparezca ninguna información sobre el arresto o la deportación de un holandés llamado Juan Ricce puede ser un indicador de éxito, al menos en lo que respecta a evitar a la justicia. Al mismo tiempo, este carácter elusivo de las fuentes hace que los esfuerzos del historiador sean casi inútiles. Si Ricce se hubiera casado o abierto un negocio, la información del registro estaría en un archivo local en México. No obstante, si cambió su identidad, como probablemente sucedió, rastrearlo es una tarea casi imposible.

\subsection{Un "negro libre" en México}

Thomas Villanueva era un "negro libre" que trabajaba como marinero en la Agata y que no regresó al barco en Veracruz antes de su viaje de regreso. Todo lo que sabemos de él es que tenía treinta años y era de estatura media, fuerte y robusto. En uno de los documentos de la Agata aparece incluido en la categoría de marineros españoles con la mención explícita de que era negro. ${ }^{42}$ Como en los casos anteriores, solo podemos especular sobre su origen, la historia de su vida y sus motivos para desertar en Veracruz. Al ser una persona de origen africano, la vida de Villanueva seguramente estaba muy ligada a la historia de la esclavitud ibérica.

¿Era Thomas Villanueva un esclavo manumitido, había comprado su libertad o, por el contrario, había nacido libre? El registro de tripulación dice que su padre también se llamaba Thomas, lo cual podría indicar que el desertor había nacido libre tal vez como hijo de un esclavo del mismo nombre, pero no podemos estar seguros. Los esclavos en el imperio español podían casarse

41. Nunn 79.

42. Juan de Rosas y Céspedes, "Lista de tripulación y equipaje del navío Olandés la Agata Galera”, marzo de 1747.TNA, Londres, High Court of Admiralty 32/94/17/SP93. 
y poseer propiedades, y si se casaban con una mujer libre sus hijos e hijas nacían libres. Este podría haber sido el caso de Thomas, aunque también podría haber nacido como esclavo en España y liberado después, o haber sido capturado en África y rebautizado como Thomas, por lo que Villanueva sería el apellido de su dueño. En todo caso, Thomas Villanueva era un "negro libre" que vivía en el sur de España, un entorno diferente al de Nueva España, Perú o el Caribe, aunque sometido a la misma legislación que el resto de los territorios de la monarquía hispánica.

A pesar de que la mayoría de los esclavos africanos comprados por particulares españoles y la corona durante los siglos XVI y XIX fueron enviados a América, aproximadamente unos 750,000 esclavos africanos negros fueron vendidos en España entre 1450 y $1750 .{ }^{43}$ La presencia de esclavos negros en España es de hecho anterior a la conquista de América, ${ }^{44}$ con muchos individuos importados por mercaderes portugueses. ${ }^{45}$ Algunos africanos negros excepcionales lograron alcanzar posiciones prominentes en la sociedad española como Juan Latino (1518-1596), el primer profesor universitario negro en Europa ${ }^{46}$ o el pintor Juan de Pareja (1606-1670). No obstante, la mayoría de ellos, aunque tuvieran el estatus de libres, estaban relegados a una posición marginal en una sociedad obsesionada con la "pureza de la sangre". ${ }^{47}$ Los esclavos y esclavas negros en la España peninsular se concentraban en pueblos y ciudades (en lugares como Cádiz, los esclavos forman aproximadamente el $10 \%$ de la población) ${ }^{48}$ y trabajaban principalmente como sirvientes domésticos para familias adineradas, que veían el tener esclavos como un símbolo de prestigio. ${ }^{49}$ Los negros de todo el país tanto esclavos como libres

43. Junto con 350,000 árabes, turcos y bereberes. Véase Alessandro Stella, "Ser esclavo y negro en Andalucía (siglos XVII y XVIII). Documentos de archivo", Tres grandes cuestiones de la historia de Iberoamérica: ensayos y monografías. Afroamérica, la tercera raíz, dir. José Andrés-Gallego (Madrid: Fundación MAPFRE TAVERA / Fundación Ignacio Larramendi, 2005) 1.

44. Joseph Harris, "The African diaspora in the Old and the New Worlds", General History of Africa:Africa from the Sixteenth to the Eighteenth Century, ed. Bethwell A. Ogot (París: UNESCO, 1992) 113-116.

45. Véase Rocío Periañez Gómez, "La introducción de los negros por la frontera extremeña y su distribución posterior", La esclavitud negroafricana en la historia de España. Siglos XVI y XVII, comps. Aurelia Martín Casares y Margarita García Barranco (Granada: Editorial Comares, 2010); Rafael M. Pérez García y Manuel F. Fernández Chaves, "Las redes de la trata negrera: mercaderes portugueses y tráfico de esclavos en Sevilla (c. 1560-1580)", La esclavitud negroafricana en la historia de España. Siglos XVI y XVII, comps. Aurelia Martín Casares y Margarita García Barranco (Granada: Editorial Comares, 2010).

46. Henry Louis Gates Jr. y Maria Wolff, "An Overview of Sources on the Life and Work of Juan Latino, the "Ethiopian Humanist"”, Research in African Literatures 29.4 (1998): 14-51.

47. Véase Max S. Hering Torres, "Limpieza de sangre en España. Un modelo de interpretación", El peso de la sangre. Limpios, mestizos y nobles en el mundo hispánico, coords. Nikolaus Böttcher y otros (México: El Colegio de México, 2011) 29-62.

48. Stella 5.

49. José Andrés-Gallego, La esclavitud en la América española (Madrid: Ediciones Encuentro / Fundación 
fueron plenamente asimilados a la dinámica de la vida social, participaban en ceremonias religiosas y establecían sus propias hermandades católicas. ${ }^{50}$ Probablemente, antes de su viaje en la Agata, Thomas Villanueva era uno de los muchos "negros libres" que vivían en la zona de la Bahía de Cádiz. ${ }^{51}$ Es posible que viviera en el lugar de origen de los propietarios, el maestre y algunos miembros de la tripulación de la Agata, Sanlúcar de Barrameda, donde había algunas familias negras y los africanos dirigían su propia capilla católica y hermandad, ${ }^{52}$ aunque no podemos estar seguros por las escasas referencias a él que encontramos en la documentación.

¿Por qué migró Thomas Villanueva a México? Si su deserción fue el resultado de un proyecto deliberado y no un accidente, ¿qué razones podrían haberle hecho dejar la Agata? Puede que hubiera decidido no regresar debido a un problema personal con uno de los miembros de la tripulación, aunque no hay evidencia de ello en los documentos de la nave. Si suponemos, por el contrario, que Villanueva planeaba emigrar a México, la deserción era la mejor manera de cruzar el Atlántico, ya que los negros estaban excluidos legal y explícitamente de la migración a las Américas. ${ }^{53}$ Precisamente por esta razón es poco probable que Villanueva tuviera contactos previos en Veracruz o el resto de México; una vez dejara el barco estaría solo. Tal vez decidió emigrar porque esperaba encontrar en México un ambiente donde una persona negra pudiera vivir decentemente con más facilidad que en Andalucía. Como la mayoría de los africanos libres, Villanueva seguramente aspiraba a mejorar su situación, poseer una casa, casarse y tal vez tener hijos. ${ }^{54}$ ¿Eran México y Veracruz un mejor lugar para alcanzar estos objetivos?

En los siglos XVI y XVIIVeracruz había sido uno de los principales puertos de entrada a México para los esclavos. Sin embargo, el comercio de esclavos mexicanos había disminuido, y en 1747 había más negros libres que esclavos en la ciudad y la región circundante; representaban entre el 14\% y el $26 \%$ de la población. ${ }^{55} \mathrm{Al}$ sur de Veracruz muchos negros libres vivían en el campo, trabajaban la tierra para

Ignacio Larramendi, 2005) 160-162.

50. Existían muchas hermandades religiosas fundadas por africanos libres y esclavizados. Véase Iván Armenteros Martínez, "De hermandades y procesiones. La cofradía de esclavos y libertos negros de Sant Jaume de Barcelona y la asimilación de la negritud en la Europa premoderna (siglos XV-XVI)", Clio, Revista de Pesquisa Histórica 29.2 (2011). https://periodicos.ufpe.br/revistas/revistaclio/article/ view/24210/19648 (21/04/2019).

51. Sería necesario buscar en el Archivo Provincial de Cádiz para ver si su nombre está incluido en cualquier documento relacionado con esclavos manumitidos o bautismos de negros nacidos libres.

52. Climent Buzón 200, 163-165.

53. "De los passageros, y licencias para ir a las Indias".

54. Stella 214.

55. Enrique Florescano y Juan Ortiz Escamilla, coords., Atlas del patrimonio natural, histórico y cultural de Veracruz, vol. 3 (Veracruz: Gobierno del Estado de Veracruz / Comisión del Estado deVeracruz / Universidad Veracruzana, 2010) 131. 
los terratenientes absentistas blancos y cuidaban el ganado. En la ciudad los negros eran también más numerosos que los europeos y una compañía de negros y mulatos se encargaba de defender Veracruz (y muchas otras ciudades). ${ }^{56}$ En todo el imperio los negros libres podían poseer propiedades y casarse, pero estaban excluidos de la representación pública y no podían ocupar cargos públicos o ejercer ciertas profesiones. ${ }^{57}$ Aun así, es posible que México y Veracruz resultasen más atractivos para Villanueva debido a la mayor proporción de habitantes negros, la existencia de comunidades rurales negras y la percepción de que era más fácil prosperar allí que en España.

Era un marinero experimentado ${ }^{58}$ que vivía en la zona de la Bahía de Cádiz, por lo que, probablemente, Thomas estaba en contacto con otros marineros que regresaban de Veracruz, quienes podrían haberle contado que había una gran población negra en la ciudad con menos limitaciones que en España. Tal vez incluso le informaron sobre la existencia de comunidades de cimarrones en las cuales los negros vivían juntos y en libertad, y resistían a las autoridades coloniales españolas. ${ }^{59} \mathrm{O}$ puede que incluso ya supiera todo esto porque ya había estado en México como esclavo, y una vez libre en España quería volver por algún motivo. ${ }^{60}$

Cualquiera que sea el caso, Villanueva hablaba español ${ }^{61}$ y probablemente entendía bien las particularidades de la cultura hispana, por lo que debe haber experimentado menos dificultades que el desertor holandés. Afortunadamente para Villanueva, en Veracruz había una gran comunidad de negros y mulatos que podían ofrecerle protección si se ganaba su confianza. ${ }^{62}$ Es difícil saber cuál fue su destino, ya que parece no haber quedado huella de él en los archivos.

56. Carmen Bernand, Negros, esclavos y libres en las ciudades hispanoamericanas (Madrid: Fundación Histórica Tavera, 2001) 114-115.

57. Bernand 93-116.

58. Ya que aparece descrito como marinero y no como grumete.

59. Véase Nicolás Ngou-Mve, "El cimarronaje como forma de expresión del África bantú en la América colonial: el ejemplo de Yangá en México”, América Negra 14 (1997): 27-51; Bernand 36-38; María Cristina Navarrete, "El cimarronaje, una alternativa de libertad para los esclavos negros", Historia Caribe 2.6 (2001): 89-98; Javier Laviña, "Cimarronaje y fracaso de la primera esclavitud en Panamá (siglos XVI-XVII)", Resistencia, delito y dominación en el mundo esclavo. Microhistorias de la esclavitud atlántica (siglos XVII-XIX), eds.Vicent Sanz Rozalén y otros (Granada: Editorial Comares, 2019).

60. Alessandro Stella documenta varios ejemplos de habitantes africanos de Andalucía que anteriormente habían estado en las Américas, algunos de ellos incluso regresaban después de estar un tiempo en Cádiz. Véase Stella 170-180.

61. Los esclavos africanos y los hombres libres negros en el Imperio español no desarrollaron una lengua criolla, probablemente debido a sus orígenes geográficos dispares y a la importancia que el lenguaje tenía para la limitada movilidad social a la que podían aspirar. Andrés-Gallego 101-102.

62. En una de las cartas de la Agata, un inmigrante español recién llegado a México se maravilla de la gran cantidad de negros y mulatos. Letter from Bartlolome de Reina in Veracruz to Román de Vargas, 16 de agosto de 1747.TNA, Londres, High Court of Admiralty 32/94/117/SP11. 


\subsection{Dos cartas de recomendación}

Aunque no consta en el registro de tripulación, parece ser que Francisco, uno de los pasajeros que viajaba en la Agata cuando fue capturada, era un emigrante que regresaba a España tras no ser capaz de encontrar empleo. Por fortuna para él, regresó con dos cartas de recomendación escritas por Diego Sáenz Rico, dos interesantes documentos que muestran, además, cómo en el siglo XVIII los socios comerciales compartían a menudo lazos de amistad. ${ }^{63}$ Las cartas son similares, aunque una de ellas contiene más elementos personales tal vez porque la relación entre remitente y destinatario es más profunda, o tal vez porque no tuvo tiempo de escribirlos en la segunda carta. Curiosamente, la misiva con elementos más personales, cuya transcripción ofrezco en primer lugar, utiliza la forma de respeto "vuestra merced", mientras que la segunda carta utiliza el más informal y personal "tú". ${ }^{64}$

Primera carta:

Amigo y señor mío,

Lo mucho que se ha ofrecido hacer con el despacho de siete registros que se regresan a ese reino es causa de no haber tenido lugar para escribir a mi señora doña Nicolasa, C.P.B. y a quien se servirá vuestra merced de decirle, que tenga esta por suya.

El amigo don Francisco que nos recomendó vuestra merced que será portador de esta, no habiendo habido en qué acomodarlo, le hemos aconsejado se regrese a ese puerto, y habiendo reconocido su buena crianza y mejores modales me da motivo para suplicar a vuestra merced encarecidamente se interese a hacerle bien procurando si llega con felicidad el que vuelva con algunas encomiendas, pues no dudo de su honrado proceder el que dará entero cumplimiento de su persona, y yo quedare a vuestra merced sumamente reconocido, y así lo espero el favor que le merezco.

Manuela y el chiquillo se mantienen con salud, y la primera se encomienda con todas veras a mi señora Doña Nicolasa, no olvidándome yo de los señores sus hijos y mi señora doña Mag. na [¿Magdalena?] a quien me encomiendo.

Vuestra merced perdone los borrones y mentiras que lleva esta, pues los registros están para salir y no falta a qué atender, y de todas maneras me repito para servir vuestra merced con todo afecto y pido a nuestro señor que en muy buena salud guarde su vida muchos años. ${ }^{65}$

Y la segunda carta:

Querido amigo,

63. Para un ejemplo bien documentado de lazos de amistad de los comerciantes españoles, véase Xabier Lamikiz, "Un 'cuento ruidoso': confidencialidad, reputación y confianza en el comercio del siglo XVIII”, Obradoiro de Historia Moderna 16 (2007): 126-127.

64. Las transcripciones están realizadas siguiendo las normas ortográficas y gramaticales del español moderno para facilitar su comprensión.

65. Diego Sáenz Rico, “Señor Don Juan Mathias Vrioso”, Veracruz, 16 de agosto de 1747. TNA, Londres, High Court of Admiralty 32/94/117/SP5. 
Lo mucho que no ignoras se ofrece que hacer en despachos, y más en el presente, que regresan a esos reinos siete registros, no me permite dilatarme, y esta [carta] solo sirve para decirte que el portador es el amigo don Francisco que recomendaste a esta casa, y no habiendo habido en qué acomodarlo, le hemos aconsejado, se vuelva para esos reinos, pero habiéndome cautivado su buena crianza y buenos modales me obliga a darle esta y suplicarte con el mayor encarecimiento te intereses a hacerlo hombre, y si llega con felicidad, el que procuras vuelva con algunas encomiendas, que no dudo de su honrado proceder dará entero cumplimiento y buena satisfacción en lo que pusieses a su cuidado, y así te repito y pido con todas veras mires por su adelantamiento, pues te lo agradeceré muchísimo.

Sabes soy tuyo de corazón y así no me detengo en expresiones, con que mándame si se te ofrece en que te pueda servir. [ilegible] pido a nuestro señor que en muy buena salud guarde tu vida muchos años. ${ }^{66}$

¿Quién era el portador de estas cartas? Solo sabemos que se llamaba Francisco. El único Francisco en la lista de tripulación de la Agata era Francisco López, escribano de 25 años incluido en la lista de oficiales por lo que es muy poco probable que las cartas de recomendación fueran para él, aunque es una posibilidad. Si algún otro Francisco viajó de regreso en la Agata, no aparece mencionado en ninguno de los documentos del barco. Empero, el Francisco de las cartas de recomendación era probablemente un adolescente, ya que en una de las cartas Sáenz pide al destinatario que haga de Francisco "un hombre". Tal vez por eso no encontramos que se le mencione.

Es probable que Francisco fuera un adolescente de una familia humilde, quizá un huérfano o el hijo de una sirvienta doméstica. Francisco fue recomendado por dos hombres, posiblemente, mercaderes de Cádiz o Sanlúcar de Barrameda. Por desgracia para él, su anfitrión en Veracruz, Diego Sáenz Rico, no pudo encontrarle una ocupación. Es de suponer que Francisco fuera enviado para ayudar a Sáenz Rico como secretario o sirviente doméstico, ya que el comerciante menciona su "educación y buenos modales" y siempre había trabajo disponible en Veracruz para cargar y descargar barcos en el puerto.

\section{Conclusión}

La migración entre Europa y América en el siglo XVIII era un fenómeno complejo y poliédrico. Más allá de la tradicional visión de la migración como un traslado neto de población peninsular al Nuevo Mundo, muchas personas iban y venían entre ambas orillas del Atlántico a menudo fuera de los canales legales. Los propios barcos que transportaban migrantes estaban operados por trabajadores emigrados, los marineros, y eran espacios de socialización entre personas de distintas nacionalidades.

66. Diego Sáenz Rico, "Señor don Pedro Nicolás Tardi”, Veracruz, 16 de agosto de 1747. TNA, Londres, High Court of Admiralty 32/94/117/SP5. 
En este artículo hemos visto cuatro historias atípicas de migración conectadas a un solo barco, la Agata Galera (1747): un marinero enfermo que quedó en tierra con permiso del capitán, dos desertores de diversos orígenes geográficos y un muchacho que intentó regresar de México a Andalucía con dos cartas de recomendación. Los cuatro hicieron al menos un viaje en la Agata, una fragata de bandera holandesa fletada por un consorcio de mercaderes de Sanlúcar de Barrameda para hacer un viaje de vuelta de Cádiz a Veracruz. Por desgracia para los implicados (y por fortuna para los historiadores), la Agata no llegó a completar su viaje, pues fue capturada por unos corsarios británicos cerca de las costas de Portugal.

Los documentos de la Agata nos ofrecen, de algún modo, una instantánea muy detallada de un momento histórico muy concreto sobre el que apenas hay registro documental adicional, especialmente, para sus protagonistas de origen humilde. A pesar de las más de 600 páginas de documentación manuscrita procedentes de la Agata que encontramos en el archivo, apenas tenemos detalles sobre cómo podía ser la vida a bordo. Sabemos que la Agata era una nave multicultural; a bordo se mezclaban españoles, holandeses, alemanes, suecos, daneses e italianos. Sin embargo, no podemos saber a ciencia cierta cómo coexistía una marinería tan diversa, ni siquiera en qué idioma hablaba la tripulación entre sí (en los documentos consta que el capitán holandés no sabía hablar español con fluidez). En todo caso, los documentos nos permiten trazar muchas historias de migración relacionadas con el barco.

Las cuatro historias particulares exploradas en la tercera parte del artículo muestran algunas de las muchas posibilidades de la migración transatlántica en el siglo XVIII. Los cuatro casos fueron sobre tripulantes de la Agata en algún momento, tres de ellos en el viaje de ida y el otro en el de vuelta. Los tres que dejaron el barco en Veracruz migraron de Europa a América de forma irregular, aunque el primero de ellos, Antonio Cordero, no fue denunciado a las autoridades. El último caso es un joven emigrante que regresa a España tras no haber sido capaz de encontrar empleo en Veracruz.

Estas y otras de las historias conectadas con la Agata muestran las posibilidades de aplicar un enfoque cualitativo a las migraciones transatlánticas sin perder de vista el contexto global. Las cifras y las estadísticas arduamente logradas por los historiadores y demógrafos son inmensamente útiles (y en ningún momento se ha tratado de negar su valía); tan solo se trata de complementar con una perspectiva adicional, microscópica, que aporte detalles que puedan pasar inadvertidos.

\section{Fuentes}

\section{Manuscritas}

The National Archives, Londres (TNA)

High Court of Admiralty

Archivo General de Indias, Sevilla (AGI)

Casa de Contratación 
Archivo Histórico Nacional, Madrid (AHN)

\section{Impresas}

Recopilación de leyes de los reynos de las Indias. Tomo 4. Madrid: Julián de Paredes, 1681.

Walker, George. The Voyages and Cruises of Commodore Walker, During the Late Spanish and French Wars. Volumen 2. London: A. Miller, 1760.

\section{Internet}

https://twitter.com

https://www.prizepapers.de

\section{Bibliografía}

Altman, Ida. "Emigrants and Society: An Approach to the Background of Colonial Spanish America". Comparative Studies in Society and History 30.1 (1988): 170-190.

."Moving Around and Moving On: Spanish Emigration in the Sixteenth Century". Migration, Migration History, History. Old Paradigms and New Perspectives. Eds. Jan Lucassen y Leo Lucassen. Bern / New York: Peter Lang, 1997.

Andrés-Gallego, José. La esclavitud en la América española. Madrid: Ediciones Encuentro / Fundación Ignacio Larramendi, 2005.

Armenteros Martínez, Iván. "De hermandades y procesiones. La cofradía de esclavos y libertos negros de Sant Jaume de Barcelona y la asimilación de la negritud en la Europa premoderna (siglos XV-XVI)". Clio, Revista de Pesquisa Histórica 29.2 (2011). https://periodicos.ufpe.br/revistas/revistaclio/article/view/24210/19648 (21/04/2019).

Bernand, Carmen. Negros, esclavos y libres en las ciudades hispanoamericanas. Madrid: Fundación Histórica Tavera, 2001.

Böttcher, Nikolaus y otros. Coords. El peso de la sangre. Limpios, mestizos y nobles en el mundo hispánico. México: El Colegio de México, 2011.

Bustos Rodríguez, Manuel. Cádiz en el sistema atlántico. La ciudad, sus comerciantes y la actividad mercantil (1650-1830). Madrid: Sílex Ediciones / Universidad de Cádiz, 2005.

Climent Buzón, Narciso. Historia social de Sanlúcar de Barrameda. En busca de nuestro pasado. Volumen 3. Sanlúcar de Barrameda: Asociación Sanluqueña de Encuentros con la Historia y el Arte, 2008.

Crespo Solana, Ana. "Legal Strategies and Smuggling Mechanisms in the Trade with the Hispanic Caribbean by Foreign Merchants in Cadiz: The Dutch and Flemish Case, 1680-1750". Jahrbuch für Geschichte Lateinamerikas 47.1 (2010): 181-212. 
Eiras Roel, Antonio. "Estructura demográfica, diversidad regional y tendencias migratorias de la población española a finales del Antiguo Régimen”. Le migrazioni in Europa, secc. XIII-XVIII.Atti delle "Settimane di Studi" e altri Convegni. Ed. Simonetta Cavaciocchi. Firenze: Le Monnier, 1994.

Florescano, Enrique y Juan Ortiz Escamilla. Coords. Atlas del patrimonio natural, histórico y cultural de Veracruz. Volumen 3.Veracruz: Gobierno del Estado de Veracruz / Comisión del Estado de Veracruz / UniversidadVeracruzana, 2010.

González Beltrán, Jesús Manuel. “Desempleo y pobreza en la agricultura de la Baja Andalucía en el siglo XVIII". Chronica Nova 37 (2011): 237-270.

. "Trabajadores agrícolas y conflictividad laboral en la Andalucía del siglo XVIII". Trocadero 17 (2005): 9-35.

Harris, Joseph. "The African diaspora in the Old and the New Worlds". General History of Africa: Africa from the Sixteenth to the Eighteenth Century. Ed. Bethwell A. Ogot. Paris: UNESCO, 1992.

Hering Torres, Max S. "Limpieza de sangre en España. Un modelo de interpretación”. El peso de la sangre. Limpios, mestizos y nobles en el mundo hispánico. Coords. Nikolaus Böttcher y otros. México: El Colegio de México, 2011.

Herzog, Tamar. Defining Nations. Immigrants and Citizens in Early Modern Spain and Spanish America. New Haven / London:Yale University Press, 2003.

Klein, Alexander y Jelle van Lottum. "The Determinants of International Migration in Early Modern Europe: Evidence from the Maritime Sector, c. 1700-1800”. School of Economics Discussion Papers 1710 (2017): 1-47.

Kuethe, Allan J. y Kenneth J. Andrien. El mundo atlántico español durante el siglo XVIII. Guerra y reformas borbónicas, 1713-1796. Bogotá: Editorial Universidad del Rosario / Banco de la República, 2018.

Laborda, Antonio y Santiago Rodríguez Aedo. Historias de la Real Armada y asociados. Prensa y corsarios españoles en la Guerra del Asiento, 1739-1748. Madrid: La Hoja del Monte, 2018.

Lamikiz, Xabier. "Un 'cuento ruidoso': confidencialidad, reputación y confianza en el comercio del siglo XVIII". Obradoiro de Historia Moderna 16 (2007): 113-142.

Laviña, Javier. "Cimarronaje y fracaso de la primera esclavitud en Panamá (siglos XVI-XVII)". Resistencia, delito y dominación en el mundo esclavo. Microhistorias de la esclavitud atlántica (siglos XVII-XIX). Eds.Vicent Sanz Rozalén y otros. Granada: Editorial Comares, 2019.

Livi-Bacci, Massimo. "The Depopulation of Hispanic America after the Conquest". Population and Development Review 32.2 (2006): 199-232.

Louis Gates Jr., Henry y Maria Wolff."An Overview of Sources on the Life and Work of Juan Latino, the "Ethiopian Humanist"”. Research in African Literatures 29.4 (1998): 14-51.

Márquez Macías, Rosario. "La emigración española a América en la época de las luces”. Españoles de ambas orillas. Emigración y concordia social. Coord. Juan 
Antonio Escudero. Madrid: Sociedad Estatal Lisboa 98, 1998. "La emigración española en el siglo XVIII a América". Rábida 10 (1991): 68-79.

Muriel, Josefina. Hospitales de la Nueva España. Fundaciones del siglo XVI. Tomo 1. México: Universidad Nacional Autónoma de México, 1990.

Navarrete, María Cristina. "El cimarronaje, una alternativa de libertad para los esclavos negros". Historia Caribe 2.6 (2001): 89-98.

Ngou-Mve, Nicolás. "El cimarronaje como forma de expresión del África bantú en la América colonial: el ejemplo de Yangá en México”. América Negra 14 (1997): 27-51.

Nunn, Charles F. Foreign Immigrants in Early Bourbon Mexico, 1700-1760. Cambridge: Cambridge University Press, 1979.

O'Reilly, William. "Movements of People in the Atlantic World, 1450-1850". The Oxford Handbook of the Atlantic World, 1450-1850. Eds. Nicholas Canny y Philip Morgan. Oxford: Oxford University Press, 2011.

Pérez García, Rafael M. y Manuel F. Fernández Chaves. "Las redes de la trata negrera: mercaderes portugueses y tráfico de esclavos en Sevilla (c. 1560-1580)”. La esclavitud negroafricana en la historia de España. Siglos XVI y XVII. Comp. Aurelia Martín Casares y Margarita García Barranco. Granada: Editorial Comares, 2010.

Periañez Gómez, Rocío. "La introducción de los negros por la frontera extremeña y su distribución posterior". La esclavitud negroafricana en la historia de España. Siglos XVI y XVII. Comp. Aurelia Martín Casares y Margarita García Barranco. Granada: Editorial Comares, 2010.

Ramos, Demetrio. "Las rutas comerciales de Indias y de América del Norte". España y el mar en el siglo de Carlos III.Vicente Palacio Atard y otros. Madrid: Marinvest, 1989.

Salamanca Rodríguez, Alejandro. “A Floating Microcosm: Histories of Transatlantic Migration in 1747”. Tesina de máster en Migraciones y Relaciones Interculturales, Universidad de Oldenburgo, 2019.

Stella, Alessandro. "Ser esclavo y negro en Andalucía (siglos XVII y XVIII). Documentos de archivo". Tres grandes cuestiones de la historia de Iberoamérica. Ensayos y monografias. Afroamérica, la tercera raíz. Dir. José Andrés-Gallego. Madrid: Fundación MAPFRE TAVERA / Fundación Ignacio Larramendi, 2005.

Torres Ramírez, Bibiano y José Jesús Hernández Palomo. Eds. Andalucía y América en el siglo XVIII. Actas de las IV Jornadas de Andalucía y América Universidad de Santa María de la Rábida, marzo-1984. Sevilla: Escuela de Estudios Hispano-Americanos de Sevilla, 1985.

Van Lottum, Jelle y otros. "Sailors, National and International Labour Markets and National Identity,1600-1850". Shipping and Economic Growth, 13501850. Ed. Richard W. Unger. Leiden / Boston: Brill, 2011.

Walker, Geoffrey J. Spanish Politics and Imperial Trade, 1700-1789. London: Palgrave Macmillan Limited, 2016. 
Zabala, Aingeru. "La vida cotidiana en los navíos de comercio". España y el mar en el siglo de Carlos III.Vicente Palacio Atard y otros. Madrid: Marinvest, 1989. 